\title{
Insuficiencia respiratoria global como forma de presentación de un hipotiroidismo. Comunicación de un caso
}

\author{
Victoria Novik A, M Eugenia Pérez O, G abriel Anwandter Za. \\ Global respiratory failure as the \\ presentation form of hypothyroidism. \\ Report of one case
}

\begin{abstract}
We report a 36 years male, admitted to the hospital for progressive respiratory failure. Chest X ray and CT scan were normal. On admission, a severe bradycardia and slow intellectual activity were noted. Serum thyroid function tests showed a TSH over 150 $\mu \mathrm{U} / \mathrm{ml}$ and T3 of $75 \mathrm{ng} / \mathrm{ml}$. Thyroid substitution therapy was associated with a progressive improvement of respiratory function. Diaphragmatic dysfunction, central hypoventilation, airway obstruction, sleep apnea and pleural effusion have been previously reported in patients with hypothyroidism. Therefore, we recommend to measure TSH in patients with unexplained respiratory failure (Rev Méd Chile 2004; 132: 81-4).
\end{abstract}

(Key Words: Hypothyroidism; Respiratory insufficiency; thyrotropin)

\begin{abstract}
Recibido el 10 de julio, 2003. Aceptado en versión corregida el 19 de noviembre, 2003. Departamentos de Endocrinología y Neumología, Servicio de Medicina del Hospital Dr. Gustavo Fricke de Viña del Mar.

Cátedra de Medicina, Facultad de Medicina, Universidad de Valparaíso.

anterno de Medicina, Universidad de Valparaíso.
\end{abstract}

\begin{abstract}
Se ha descrito que el hipotiroidismo puede Ooriginar una insuficiencia respiratoria crónica en individuos sin enfermedad pulmonar conocida. Esta inusual complicación se ha atribuido a: 1) una alteración en la expresión génica de las cadenas de miosina de la musculatura estriada del diafragma y de los músculos toráxicos por la falta de hormonas tiroideas ${ }^{1-4}$; 2 ) una respuesta ventilatoria disminuida frente a la hipoxemia e hipercapnia ${ }^{5,6}$; 3) obstrucción de la vía aérea ${ }^{7}$;) apnea obstructiva del sueño ${ }^{8}$; 5) alteraciones del intercambio gaseoso por anormalidad de la membrana alvéolo-capilar ${ }^{9}$ y 6) derrame pleural.
\end{abstract}

Correspondencia a: Dra. Victoria Novik A. Asturias 1750, casa 6. Viña del Mar alto. Fax: 32-675014.

E mail: chavez.novik@entelchile.net
Comunicamos el caso de un hombre joven que presentó disnea durante meses hasta que fue hospitalizado por una insuficiencia respiratoria, sin que se encontrara una patología orgánica que la explicara, salvo un hipotiroidismo severo. La terapia de sustitución con hormona tiroidea logró revertir rápidamente su insuficiencia respiratoria.

\section{CASO CLÍNICO}

Varón de 36 años, proveniente de una zona rural de Petorca, Quinta Región, quien presentaba hacía dos meses una disnea de esfuerzo progresiva asociada a tos, al arrear sus cabras por el cerro, labor que realizaba previamente sin ninguna limitación durante muchos años. Consultó al hospital por 
disnea de pequeños esfuerzos, tos y compromiso del estado general. Fue hospitalizado en Petorca donde se interpretó el cuadro como una neumonía, prescribiéndose un antimicrobiano y nebulizaciones con un broncodilatador. Evolucionó con una falla respiratoria progresiva por lo que fue trasladado a Viña del Mar, al Hospital Dr. Gustavo Fricke. A su ingreso el paciente relató una historia de astenia, adinamia y edema facial, que vendría presentando en forma levemente progresiva, desde hacía dos años. Negó tener un hábito tabáquico. El tránsito intestinal era normal. Al examen físico destacaron: obesidad (IMC: $30 \mathrm{~kg} / \mathrm{m}^{2}$ ), bradicardia, bradilalia, presión arterial $110 / 70 \mathrm{mmHg}$, temperatura axilar $36,3^{\circ} \mathrm{C}$, edema facial, respiración de tipo abdominal, disminución global del murmullo pulmonar y en las extremidades inferiores, ausencia de edema y reflejos osteotendíneos con relajación lenta. Los exámenes de laboratorio mostraron en los gases arteriales: hipoxemia $\left(\mathrm{PaO}_{2}: 59 \mathrm{mmHg}\right)$, hipercapnia $\left(\mathrm{PaCO}_{2}: 69 \mathrm{mmHg}\right)$, saturación de $\mathrm{O}_{2}: 85 \%$ y una acidosis respiratoria compensada ( $\mathrm{pH}: 7,37$, bicarbonato: $21 \mathrm{mEq} / \mathrm{l}$ ). Las pruebas de función tiroidea mostraron: TSH $>150 \mu \mathrm{UI} / \mathrm{ml}(0,27-4,20)$, T3: $\quad 0,75 \quad \mathrm{ng} / \mathrm{ml} \quad(0,8-2,0) \quad$ (Electroquimioluminiscencia; Elecsys 1010 Roche Laboratories). Los anticuerpos antitiroideos fueron negativos (inmunofluorescencia indirecta). Un hemograma mostró una anemia macrocítica leve, la determinación de CK total fue normal. Una radiografía de tórax mostró una cardiomegalia con campos pulmonares sin alteraciones. El scanner de tórax confirmó la normalidad pulmonar. La serología para Chagas fue positiva; en título de 1:80 (inmunofluorescencia indirecta). Un ecocardiograma mostró una contrac- tibilidad normal con una fracción de eyección de $50 \%$, evidenciando una hipertensión pulmonar (presión media: $45 \mathrm{mmHg}$ ) y reflujo tricuspídeo leve, sin derrame pericárdico. Una endoscopia digestiva alta fue normal y los anticuerpos anticélulas parietales negativos (inmunofluorescencia indirecta sobre corte de estómago de rata). La espirometría evidenció una capacidad vital forzada de $37 \%$, un volumen espiratorio forzado en el primer segundo (VEF1) de 26\%, un VEF1/CVF $57,8 \%$ y FEMM 12 L/min; no modificables con un broncodilatador en aerosol.

Se inició terapia de sustitución tiroidea en dosis crecientes, observándose desaparición de los síntomas respiratorios y normalización de la gasometría arterial (Figura 1). Fue dado de alta al mes de hospitalización bajo terapia con $200 \mu \mathrm{g} /$ día de levotiroxina y salbutamol en inhalador. A los tres meses del inicio del tratamiento, el paciente se encontraba asintomático, había desaparecido la bradipsiquia, el IMC se había normalizado $\left(26 \mathrm{~kg} / \mathrm{m}^{2}\right)$ y había reanudado su pastoreo por los cerros sin la aparición de disnea ni tos. Por ello, se le indicó la suspensión del broncodilatador y la mantención de la levotiroxina en igual dosis. Un año más tarde, estando en tratamiento con levotiroxina, persistía asintomático, el hemograma se había normalizado, un nuevo ecocardiograma mostraba desaparición de la hipertensión pulmonar como del reflujo tricuspídeo y la espirometría mostraba una mejoría notable: CVF 61\%, VEF1 42\%, VEF/CVF 55\% FEMM 20 l/min. Cabe destacar que Petorca es una zona endémica de enfermedad de Chagas, considerándose al paciente como un portador asintomático.

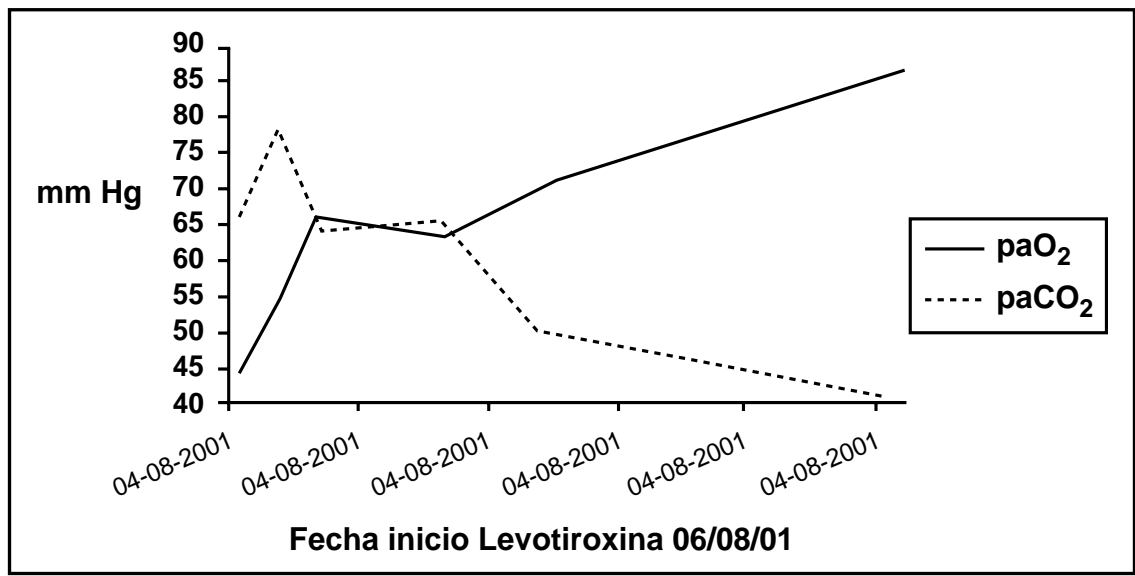

FiguRA 1. Evolución gasométrica bajo terapia de reemplazo tiroideo. 


\section{DisCUSIÓN}

En pacientes con hipotiroidismo se han descrito una serie de manifestaciones respiratorias: disnea de ejercicio, tos y fatigabilidad frente al ejercicio, apnea obstructiva del sueño, obstrucción de la vía aérea, disminución de la respuesta ventilatoria frente a la hipoxia e hipercapnia, disminución de la presión inspiratoria, derrame pleural y disfunción diafragmática ${ }^{3-9}$.

Se ha comunicado en el hipotiroidismo una relación elevada entre la presión final inspiratoria y la presión máxima transdiafragmática, una debilidad diafragmática y una hipoventilación alveolar, situaciones todas que son reversibles con la terapia de reemplazo tiroide $0^{10}$. La disfunción diafragmática es relativamente frecuente, pudiendo ser de severidad variable ${ }^{10-12}$.

Desde hace muchos años se conoce también, que el hipotiroidismo puede asociarse a una miopatía periférica ${ }^{10-14}$. Los genes que codifican las cadenas pesadas de miosina tienen distintas posibilidades de expresión: alfa/alfa, alfa/beta, beta/beta. El predominio de estas isoformas determina la calidad de la contracción de la musculatura estriada. En el hipotiroidismo, no solo se reduce la calidad de la miosina sino también la cantidad, lo que resulta en un deterioro de la contractibilidad muscular $2,3,5,10$. La relajación muscular depende de la disminución del calcio en el citosol, lo que es mediado por la ATPasa cálcica en el retículo sarcoplásmico. La carencia de T3 dificulta la transcripción de los genes de esta ATPasa, lo que interfiere en una adecuada relajación muscular ${ }^{15}$.

El compromiso del diafragma en el hipotiroidismo, no sólo sería de tipo muscular, por las alteraciones ya descritas, sino que también se debería a un compromiso nervioso. Se ha descrito inexcitabilidad, fibrosis y desmielinización en el nervio frénico ${ }^{12,16}$, alteraciones que se han revertido con la normalización de los niveles de T3. También se han descrito alteraciones en los otros músculos respiratorios en el hipotiroidismo, tanto en inspiración como en espiración. Estos se pueden constatar en alteraciones en la capacidad vital y en el VEF1 en la espirometría. Estos desaparecen con el empleo de tiroxina, pero pueden demorar varios meses en hacerlo ${ }^{14}$.
La hipercapnia observada en el hipotiroidismo se ha atribuido a la disfunción diafragmática ${ }^{10} \mathrm{y}$ también a una alteración del intercambio gaseoso, originada en una disminución en el número y tamaño de los capilares pulmonares y/o por un engrosamiento de la pared alvéolo-capilar. Estas alteraciones también revierten con el empleo de hormona tiroidea ${ }^{17}$. En una serie de 38 pacientes hipotiroideos se observó una respuesta inadecuada a la hipercapnia en $34 \%$ e inadecuada frente a la hipoxia, en $27 \%$ de ellos. La administración de hormona tiroidea revirtió estas respuestas anormales, incluso dentro de la primera semana de la terapia ${ }^{5}$.

La apnea del sueño descrita en pacientes con hipotiroidismo puede ser de origen central ${ }^{5}$ como obstructiva, por estrechez de las vías aéreas como resultado del depósito de mucopolisacáridos y la extravasación de proteínas en los tejidos bronquiales ${ }^{7}$. La obesidad, frecuentemente asociada al mixedema, es más frecuente en los pacientes que presentan apnea del sueño.

Por último, el hipotiroidismo puede provocar hiperreactividad bronquial en sujetos no asmáticos, observándose una relación inversa entre los niveles de función tiroidea y la respuesta a betaadrenérgicos. La causa de este trastorno no se conoce $^{18,19}$.

En el paciente que comunicamos, el hipotimoidismo primario puede ser responsable de toda su sintomatología, siendo causa suficiente para explicar su insuficiencia respiratoria. Incluso, las alteraciones cardíacas evidenciadas en la ecocardiografía, que revirtieron bajo tratamiento con levotiroxina, pueden tener como única causa el hipotiroidismo ${ }^{2}$. Es probable que la corrección de la miopatía diafragmática con la terapia de reemplazo tiroidea sea responsable de la mejoría en la tolerancia al ejercicio y la corrección de la hipercapnia, dado que no recibió ninguna otra terapia complementaria. La velocidad en la corrección de la gasometría ocurrió al igual que en otros pacientes reportados en la literatura ${ }^{5}$.

En este paciente no observamos la presencia de apnea del sueño pero sí evidencia de obstrucción bronquial, la cual al año de tratamiento aún no había desaparecido totalmente. Esta alteración puede ser de más lenta resolución que los otros trastornos respiratorios presentes en el hipotiroi- 
dismo, pero no puede descartarse que en este paciente se deba a un asma bronquial preexistente, que el paciente ignoraba.

La comunicación de este caso nos permite proponer que el hipotiroidismo debiera ser consi-

\section{REFERENCIAS}

1. BRENT GA. The molecular basis of thyroid hormone action. N Engl J Med 1994; 331: 847-53.

2. Novik V, Cárdenas I, Gonzáalez R, Peña M, López JM. Insuficiencia cardíaca grave como complicación de hipotiroidismo primario. Rev Méd Chile 1996; 124: $1248-50$.

3. Sieck G, Wilson L, Johnson B, Zhan WZ. Hypothyroidism alters diaphragm muscle development. J Appl Physiol 1996; 81: 1965-72.

4. Bellemare F, Grassino A. Evaluation of human diaphragmatic fatigue. J Appl Physiol 1982; 53: 1196-206.

5. Ladenson PW, Goldenheim PD, Ridghay EC. Prediction and reversal of blunted ventilatory responsiveness in patients with hypothyroidism. Am J Med 1988; 84: 877-83.

6. FREEDMAN S. Lung volumes and distensibility, and maximum respiratory pressures in thyroid disease before and after treatment. Thorax 1978; 33: 78590.

7. Rajagopal $\mathrm{K}$, Abbrecht $\mathrm{P}, \mathrm{Derderian} \mathrm{S}$, Picket $\mathrm{CH}$, Hofeid F, Teшs C, Zwiшch C. Obstructive sleep apnea in hypothyroidism. Ann Intern Med 1984; 101: 491-4.

8. Milman RP, Bevilacqua J, Peterson DD, Pack Ai. Central sleep apnea in hypothyroidism. Am Rev Respir Dis 1983; 127: 504-7.

9. SACHDEV Y, HaL R. Effusions into body cavities in hypothyroidism. Lancet 1975; 1: 564-5.

10. Martínez F, Bermúdez-G, Ceш B. Hypothyroidism. A reversible cause of diaphragmatic dysfunction. Chest 1989; 96: 1059-63. derado como una posibilidad diagnóstica en todo caso de insuficiencia respiratoria de causa oscura o frente a la ausencia de respuesta terapéutica a las medidas habituales. El costo de dicho diagnóstico es escaso al igual que el de su tratamiento.

11. Astrom KE, Kugelberg E, Muler R. Hypothyroid myopathy. Arch Neurol 1961; 5: 26-36.

12. Laroche CM, Cairns T, Moxham J, Green M. Hypothyroidism presenting with respiratory muscle weakness. Am Rev Respir Dis 1988; 138: 472-4.

13. Weiner M, Chausow A, Szidon P. Reversible respiratory muscle weakness in hypothyroidism. $\mathrm{Br} \mathrm{J}$ Dis Chest 1986; 80: 391-5.

14. Siafakas NM, Salesiotou V, Filaditaki V, Tzanakis N, Thalassinos N, Bouros D. Respiratory muscle strength in hypothyroidism. Chest 1992; 102: 189-94.

15. Seppet EK, Kolar F, Dixon IM, Hata T, Dhalia NS. Regulation of cardiac sarcolemmal $\mathrm{Ca} 2+$ channels and $\mathrm{Ca} 2+$ transporters by thyroid hormone. Mol Cell Biochem 1993; 129: 145-59.

16. Rao SN, Katiyar BC, Nair KR, MisRa S. Neuromuscular status in hypothyroidism. Acta Neurol Scand 1980; 61: 167-77.

17. IngBaR DH. The respiratory system. In: Ingbar SH, Braverman LE, eds. The Thyroid. Philadelphia: JP Lippincott Co 1986; 1130-39.

18. Wieshammer S, Keck FS, Schauffeien AC, von Beauvais $\mathrm{H}$, Seibold $\mathrm{H}$, Hombach V. Effects of hypothyroidism on bronchial reactivity in non-asthmatic subjects. Thorax 1990; 45: 947-50.

19. HarRison RN, Tattersfield AE. Airway response to inhaled salbutamol in hyperthyroid and hypothyroid patients before and after treatment. Thorax 1984; 39: 34-9.

\section{Agradecimientos}

Agradecemos al Dr. Jorge Vega Stieb su valiosa cooperación en la corrección del manuscrito, y su entusiasmo para impulsarnos a comunicarlo. 